HUMANAS E SOCIAIS

V.9 • N.2 • 2021 • Fluxo Contínuo

ISSN Digital: 2316-3801

ISSN Impresso: 2316-3348

DOI: 10.17564/2316-3801.2021v9n2p527-539
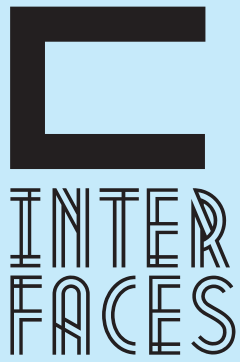

CIENTÍFICAS

\title{
O QUE SUSTENTA O INSUSTENTÁVEL? REFLEXÕES DE UM DESENVOLVIMENTO APOIADO NA POBREZA ENA DESIGUALDADE
}

WHAT SUSTAINABLES SUSTAINABLE? REFLECTIONS FROM DEVELOPMENT SUPPORTED BY POVERTY AND INEQUALITY

\section{¿QUÉES SOSTENIBLE? REFLEXIONES DE DESARROLLO APOYADAS SOBRE LA POBREZA Y LA DESIGUALDAD}

Barbara Oliveira de Morais Alexandre Ferreira Lopes ${ }^{2}$

\section{RESUMO}

0 presente ensaio teve como objetivo refletir acerca das questões que permeiam a busca por um desenvolvimento sustentável e que culminam no aprofundamento da desigualdade e da pobreza. Em um esforço para demonstrar os efeitos da injustiça ambiental e da (in)sustentabilidade, uma vez que a exclusão e a pobreza crescem cada vez mais, provocando distanciamentos e o aprofundamento das desigualdades em diferentes dimensões (social, ambiental e econômica) é que este ensaio foi estruturado. A partir dos conceitos encontrados neste ensaio percebeu-se que a questão da desigualdade ambiental é indissociável da desigualdade social e por essa razão a problemática ambiental nos últimos anos se tornou uma discussão necessária, urgente e imprescindível, visto que é preciso reestabelecer o diálogo acerca dos riscos ambientais que os mais pobres estão suscetíveis.

\section{PALAVRAS-CHAVE}

Desigualdade. Pobreza. Injustiça Socioambiental. Desenvolvimento Insustentável. 


\section{ABSTRACT}

This essay aimed to reflect on the issues that permeate the search for sustainable development and that culminate in the deepening of inequality and poverty. In an effort to demonstrate the effects of environmental injustice and (un)sustainability as exclusion and poverty grow increasingly, causing distances and deepening inequalities in different dimensions (social, environmental and economic) is that this essay was structured. From the concepts found in this essay, it was realized that the issue of environmental inequality is inseparable from social inequality and for this reason the environmental issue in recent years has become a necessary, urgent and essential discussion, since it is necessary to reestablish the dialogue about the environmental risks that the poorest are susceptible to.

\section{KEYWORDS}

Inequality. Poverty. Social and Environmental Injustice. Unsustainable Development.

\section{RESUMEN}

Este ensayo tuvo como objetivo reflexionar sobre los temas que permean la búsqueda del desarrollo sostenible y que culminan en la profundización de la desigualdad y la pobreza. En un esfuerzo por demostrar los efectos de la injusticia ambiental y la (des) sostenibilidad a medida que la exclusión y la pobreza crecen cada vez más, provocando distancias y profundizando las desigualdades en diferentes dimensiones (social, ambiental y económica) es como se estructuró este ensayo. A partir de los conceptos encontrados en este ensayo, se percató que el tema de la desigualdad ambiental es inseparable de la desigualdad social y por ello el tema ambiental en los últimos años se ha convertido en una discusión necesaria, urgente e imprescindible, ya que es necesario restablecer el diálogo sobre los riesgos ambientales a los que son susceptibles los más pobres.

\section{PALABRAS CLAVE}

Desigualdad. Pobreza. Injusticia socioambiental. Desarrollo insostenible. 


\section{INTRODUÇ̧̃̃o}

Embora a pobreza e a desigualdade caminhem de mãos dadas, são questões distintas, que enquanto área de pesquisa permite diferentes discussões a respeito. Sendo assim, nesse trabalho, há um esforço em dialogar sobre a desigualdade e a pobreza como um efeito da busca por um dito chamado "Desenvolvimento Sustentável”. Preliminarmente, é interessante destacar que os pressupostos aqui assumidos são interpretações oriundas de pesquisa desenvolvida durante o mestrado que permitiu uma análise reflexiva e também crítica frente ao tema.

Faz-se necessária, portanto, a compreensão inicial de que no campo da Sustentabilidade, desde o relatório de Brundtland (1987), que foi um marco referente à definição de Desenvolvimento Sustentável, países desenvolvidos e subdesenvolvidos como o Brasil resolveram adotar um discurso voltado as preocupações com o meio ambiente aliando tais preocupações a um desenvolvimento econômico "sustentável" - ainda que na maior parte das vezes a intenção e o discurso se refiram a crescimento econômico (SANTANA, 2012; SCHRODER et al., 2015).

Na prática, a busca pelo desenvolvimento tem se mostrado insustentável, uma vez que se subsidia em três pilares: desenvolvimento como crescimento econômico, desenvolvimento como satisfação das necessidades básicas e desenvolvimento como elemento de sustentabilidade socioambiental. E embora a preocupação socioambiental seja evidenciada a preocupação principal é o de crescimento econômico e no modelo econômico que vivemos, a questão está centrada no lucro baseada em uma sociedade industrial, urbana e detentora de riqueza (SANTOS et al., 2012).

Cumpre ressaltar, que as reflexões aqui apresentadas decorrem do processo de formação realizado em um programa de pós-graduação que desde sua fundação no ano de 2010 assume como propósito desenvolver habilidades para trabalhar questões relacionadas ao desenvolvimento econômico, social e ambiental em diferentes escalas, tendo como foco a redução da pobreza e das desigualdades sociais.

Nessa perspectiva, devido as tensões e dilemas existentes sobre os temas aqui apresentados objetivou-se nessa oportunidade refletir acerca dos efeitos do crescimento a qualquer custo, sem a preocupação com as questões sociais, ambientais e econômicas - nessa ordem - que reproduzem as condições de vulnerabilidade social e econômica que atinge diariamente os mais pobres. Caracterizando-se, portanto, como mais uma apropriação do capitalismo a um discurso de proteção e "avanço" que visa perpetuar sem maiores modificações as relações de poder já existentes.

O capital e o discurso desenvolvimentista assumiram o papel de reproduzir na sociedade as injustiças socioambientais (AMBIVERO, 2016). E para que haja a superação dos efeitos das desigualdades e superação da pobreza é necessária uma ruptura com tais práticas, visto que, locais com alto índice de pobreza viram zonas de sacrifício, acentuando as discriminações, não só do ponto de vista social, mas também ambiental (LOPES, 2015). 


\section{MÉTODO}

Este ensaio teórico traz uma análise reflexiva acerca das questões relacionadas à pobreza e desigualdade, que são efeitos das transformações sociais realizadas ao longo da história. Apresentaram-se aqui reflexões oriundas das mudanças nas formas de distribuição de riqueza e nas injustiças socioambientais oriundas desse processo.

Dessa forma, como fonte de dados deste ensaio teórico, recorreu-se a produções apreciadas a partir da busca na literatura em bases de dados científicos com o uso dos descritores "Injustiça Socioambiental”, “Desigualdade e Pobreza" e "Desigualdade Ambiental”, bem como, provenientes de livros, artigos, dissertações e teses sobre a temática.

Adotou-se, no presente estudo, para atender ao objetivo proposto, o entendimento de que o modelo capitalista trabalha o desenvolvimento como um slogan de avanço, em que sociedades atrasadas serão conduzidas para modelos de sociedades avançadas, em que primeiramente se acumula e posteriormente se distribui (SANTOS et al., 2012).

Assim sendo, há um esforço em trazer os principais conceitos referentes a essas questões, para que haja a reflexão de maneira mais crítica sobre os efeitos do crescimento econômico e do desenvolvimento no modelo capitalista configurado como insustentáveis (BARONI, 1992).

\section{RESULTADOS E DISCUSSÕES}

É certo que ao tratarmos de pobreza e de desigualdade há confusões. Na pesquisa de Escorel (1999) a autora definiu que a desigualdade social possui um conceito relativo, segregando a pobreza em duas partes: a relativa e a absoluta. Na primeira, se deve à falta de recursos ou de consumo. $\mathrm{Na}$ segunda, é a falta de acesso aos bens e serviços. Por essa razão, na literatura há diversas produções que ao se referirem à pobreza absoluta se referem à desigualdade, compreendendo que devido às questões desiguais tanto sociais, econômicas e ambientais é que um indivíduo permanece pobre (BARROS; MACHADO; MENDONÇA, 1997).

Para se entender a questão de desigualdade social no Brasil é necessário refletir sobre o avanço do projeto de industrialização e de mercadificação social que apoiado no discurso neoliberal de globalização, concebeu socialmente uma ilusória imagem do conceito de desenvolvimento, com promessas de melhoria social por meio da geração de renda e do pleno e digno emprego (ABDALLA; FARIA, 2014).

Para Soares (2009) a América Latina foi influenciada pelos ajustes neoliberais que trouxeram um custo social elevado, pagos principalmente por países como o Brasil. Ao situarmos a década de 1960 a 1980, esse período foi marcado por um modelo desenvolvimentista-conservador-autoritário, que visava à promoção de um "desenvolvimento" sem que houvesse transformações nas relações da sociedade, da maneira como diferentes classes sobreviviam principalmente devido ao projeto de desenvolvimento industrial do país. 
Até o final da década de 1980, por exemplo, havia a vinculação dos direitos sociais ao sistema previdenciário, sendo assim, existia uma tensão entre a manutenção da estrutura de privilégios e a necessidade de extensão de direitos sociais. Com a promulgação da Constituição de 1988, as políticas sociais ganharam maior força e a partir de então há uma correlação histórica em relação às mudanças e ampliação do acesso e garantia dos direitos.

Muito embora a constituição cidadã de 1988 tenha de maneira formal e expressa previsto o direito a um meio ambiente saudável e ecologicamente equilibrado e tenha expressado a defesa de um conjunto de direitos sociais que deveriam ser efetivados por meio de políticas sociais, na prática, muitas conquistas não saíram do papel com a qualidade necessária.

Já a reforma do Estado que ocorreu na década de 1990, condenou à pobreza largas parcelas da população, não é de hoje que temos uma complexa relação entre democracia política e democracia social. Cohn (1999) há mais de duas décadas questionava como compatibilizar democracia e desenvolvimento, demonstrando que o desenvolvimento desigual é resultado inevitável do livre mercado.

Muitos associam à desigualdade a escassez, mas na verdade o que existe é a miséria e as leis do mercado se tornam inoperantes visto que sua racionalidade supõe a igualdade de oportunidades para que haja a competição e esse pressuposto não é gerado pelo mercado, sendo, portanto, uma relação desfavorável aos mais pobres, uma vez que propaga a privatização da área social baseado em um modelo de desenvolvimento que privilegia a oferta produtiva em detrimento das demandas sociais, prejudicando os mais pobres.

A exclusão que expõe indivíduos a um projeto de desenvolvimento baseado em um modelo precário, instável e marginal de vida é fruto do modo de operacionalização do capitalismo "um modo de vida do excluído que não consegue ser reincluído" (PAUGAM et al., 1999, p. 30).

Esse processo é visto por Soares (2009) como uma transformação produtiva sem equidade que provocou um agravamento das desigualdades e ocasionou a exclusão. No tocante as desigualdades, estas são, portanto, fruto dos conflitos históricos e das configurações de classe e dominação.

Nesse sentido, pensar nas contradições do capital que tem como objetivo a exploração, expropriação e destruição humana, social e ambiental, possibilita refletir em como a produção e o consumo expressam a correlação de forças presentes na sociedade (NINO, 2019).

Trabalhos recentes como o de Loureiro (2019) destacaram o caráter classista inerente do capitalismo em que a propriedade dos meios de produção é para poucos indivíduos, condicionando a maior parte da população a estarem “[...] mercê das margens de lucro e dos baixos salários em condições que beiram a subsistência e das diferentes formas de expropriação que são necessárias à acumulação do capital e a reprodução social” (LOUREIRO, 2019, p. 35).

Nesta perspectiva, no que diz respeito à exclusão social, Nascimento (2000) entende que o processo de exclusão se refere a uma ruptura dos vínculos sociais, elencadas a partir de três variáveis, sendo a primeira delas uma concepção ampla, aproximada das diferentes formas de discriminação ou rejeição social no quais indivíduos e grupos vivenciam - é o caso dos negros, nordestinos, pobres, minorias sexuais e religiosas, sem-terra, catadores de materiais recicláveis, que são grupos excluídos.

Em seguida, compreende-se a exclusão social como a que prolifera a exclusão dos direitos, visto que trabalhadores pobres, sem trabalhos formais ou desempregados, não são integrados ao mundo do trabalho, sobrevivendo em condições mínimas de vida, não inseridos socialmente. 
E, por último, a concepção que trata de um novo modelo de exclusão social, referindo-se a exclusão de direitos para a recusa ao espaço de direito, vide grupos como indígenas e da população em situação de rua, pois passam a não ter diretos, sendo objeto de extermínio. (NASCIMENTO, 2000).

Outros autores se debruçam na discussão da desigualdade e da pobreza como um modelo de dominação capitalista que objetiva a divisão de classe, a exploração de mão de obra do trabalhador, a profunda concentração de renda no país culminando em um processo de exclusão social, porque banalizam a desigualdade permitindo que o processo de exclusão social avance. (VIEIRA, 2009).

A figura do Estado nesse processo é relevante, pois se configura como uma mão do capital para a continuidade desses processos de exclusão, vide o trabalho de Cohn (1999), que há mais de três décadas apontava a qualidade das políticas sociais enquanto ferramenta para a construção da cidadania e da autonomia dos sujeitos vulnerabilizados.

Scalon (2011) analisou no tocante as questões da desigualdade, da pobreza e das políticas públicas enfatizando que a desigualdade não é um fato natural, mas uma construção social, sendo resultado das escolhas políticas feitas ao longo da história de cada sociedade.

$\mathrm{Na}$ análise das produções sobre precariedade e exclusão as injustiças socioambientais são conceituadas como um desdobramento da desigualdade socioambiental. Para ilustrar, Almeida e Gurgel (2018) defendem que para compreendermos a justiça ambiental é necessário um entendimento da importância do meio ambiente, mas não apenas pela parte ecológica e sim sob uma perspectiva da inter-relação pessoa-ambiente, que em linhas gerais significa que o indivíduo é parte integrante e inseparável do meio.

Assim, a justiça ambiental traz a noção de que há a busca pelo tratamento justo, da participação de todos no processo de elaboração, desenvolvimento, implementação e adequação de projetos, políticas e legislações ambientais, mas não se restringem a essas questões. A justiça ambiental abrange questões sociopolíticas, culturais, jurídicas, econômicas, de direitos humanos e ética ambiental (DE ALMEIDA; GURGEL, 2018).

O problema ambiental está associado ao modo de produção capitalista, uma vez que a exploração do homem pelo homem e da natureza pelo homem é inerente ao sistema. 0 problema da degradação ambiental não pode ser resolvido apenas com mudanças políticas e morais. Para que haja uma mudança efetiva, que não seja apenas paliativa são necessárias reiteradas mudanças nas relações sociais e materiais.

Na visão de Herculano (2002) a justiça ambiental representa a oportunidade de se tratar as questões de desigualdades sociais no campo ambiental. Sendo assim, justiça ambiental não se trata apenas da instituição de leis ambientais, mas da discussão e articulação de temas voltados à justiça social articulando-as. (HERCULANO, 2002; ACSELRAD, 2005; LAYRARGUES, 2009; ALMEIDA; GURGEL, 2018).

Em relação aos impactos da exploração ambiental desenfreada e dos efeitos sociais desencadeados, percebe-se que quem mais os sentem são os sujeitos mais vulnerabilizados, pois determinados grupos são mais submetidos do que outros, a níveis significativos de riscos, a uma exploração socioambiental em troca de condições precárias de trabalho e moradia. Loureiro (2003, p. 51) conceitua esses grupos como os que se encontram em um estado de vulnerabilidade socioambiental, posto que esses grupos se encontram em: 
[...] maior grau de dependência direta dos recursos naturais para produzir, trabalhar e melhorar as condições objetivas de vida; excluídos do acesso aos bens públicos socialmente produzidos, e ausentes de participação legítima em processos decisórios no que se refere à definição de políticas públicas que interferem na qualidade do ambiente em que se vive.

Para se entender a relação entre justiça ambiental e desigualdade ambiental, Layrargues (2009) cita que tanto a injustiça ambiental quanto a desigualdade ambiental decorrem do conflito de interesses individuais e coletivos. Sendo assim, tais conflitos são o pano de fundo das questões ambientais, visto que desencadeiam decisões que devido um conjunto de valores, crenças e interesses comerciais, econômicos e ambientais geram impactos para o coletivo.

No que se refere aos riscos socioambientais, observa-se que as populações de baixa renda, os grupos raciais que constantemente sofrem discriminação, os povos originários, quilombolas, moradores de bairros operários, populações marginalizadas e vulneráveis, são as que recebem a maior carga de danos ambientais. Isso se deve as práticas adotadas em nome de um modelo de desenvolvimento insustentável que se propõe a acumulação de riquezas de uns, em prol do detrimento da preservação socioambiental de outros (LAYRARGUES, 2009; LOUREIRO, 2019).

Observa-se, portanto, que os conflitos socioambientais são disputas derivadas dos tipos de relações variadas que determinados grupos possuem com o meio natural em que estão inseridos, englobando desde estruturas sociais e ambientais instáveis, até a clivagem entre esses dois mundos (LITTLE, 2001).

Assim sendo, corrobora-se com o pensamento de Layrargues (2009) ao afirmar que a questão ambiental dentre outros fatores se relaciona a questão de justiça distributiva, uma vez que há a possibilidade da eliminação das desigualdades que são desencadeadas pelos conflitos socioambientais. Para o autor, há uma ponte que liga a justiça distributiva para a eliminação da desigualdade. E ao pensarmos em justiça distributiva é necessário frisar o papel dos movimentos sociais pela luta desses direitos e pela promoção dessa pauta.

Entretanto, a luta por direitos muitas vezes é silenciada, visto que o processo de luta está ligado ao território e se relaciona às diferentes formas de apropriação, uso e significação do mesmo (VILAÇA; LOPES, 2018). Neste sentido, é preciso garantir que a justiça ambiental seja promovida para que a desigualdade ambiental seja minimizada, sobretudo para que haja interação entre temas sociais e ambientais, visto que a problemática socioambiental é fruto de uma modernidade danificada. (GIDDENS, 2002).

Para que os espaços sejam ocupados pelos que foram injustiçados ambientalmente é preciso que as classes menos privilegiadas - que todo esse tempo foi submetido a riscos e vulnerabilidades socioambientais - sejam incluídas em um projeto social que priorize a efetiva melhoria de vida desses sujeitos. Assim, é preciso que o processo de construção da cidadania seja primeiramente reconhecido pelos vulneráveis, para que estes possam se reconhecer como sujeitos sociais ativos, aliando-os a uma sociedade preocupada com as transformações de vida dessas pessoas, sendo fruto de um processo de convivência com esses cidadãos que se recusam a permanecer nos lugares que the foram definidos sociais, cultural e ambientalmente (DAGNINO, 1994).

Como já referido, o modelo de desenvolvimento adotado, mascarado pelo modelo de crescimento, embora seja produto das mudanças globais ambientais e socioeconômicas está relacionado também 
ao que se faz e ao que se deixa de fazer, determinando condições de vida desses sujeitos. Portanto, percebe-se que a ação e a inação da sociedade, a intervenção ou a falta de intervenção social são questões inerentes à perpetuação ou a ruptura dos processos intensos de submissão de classes menos privilegiadas ao modelo de produção e consumo do/no espaço (ALVES, 2017).

A esse respeito, é possível a ampliação do diálogo sobre a promoção da Justiça socioambiental por meio da Educação Ambiental Crítica, que se configura como uma ferramenta de promoção e estímulo da participação social, tendo um caráter transformador.

Para Carvalho (1995) a educação ambiental é estratégica, devido ao “ambiental” ser capaz de estimular o diálogo entre educação e movimentos sociais, mobilizando, assim, os atores para que o processo de democratização da sociedade seja pautado em soluções de fato sustentáveis.

Na perspectiva de Jacobi, Tristão e Franco (2009) vivemos em uma sociedade de risco, crescentemente ameaçada e afetada pelos agravos socioambientais. Para os autores,

[...] as práticas educativas ambientalmente sustentáveis nos apontam para propostas pedagógicas centradas na criticidade e na emancipação dos sujeitos, com vistas à mudança de comportamento e atitudes, ao desenvolvimento da organização social e da participação coletiva. (JACOBI; TRISTÃO; FRANCO, 2009, p.).

Marx (1999) sinalizou a ausência de livre escolha que a classe operária possui e em que a maior parte das atividades é determinada pelas condições sociais, ambientais e históricas vivenciadas. Tamanhas transformações embora pareça utópica, visto que pensar nas contribuições da educação ambiental para a redução das desigualdades é um desafio, salienta-se que os riscos socioambientais que a maior parte da população está submetida se deve exatamente a ausência de escolha que os indivíduos possuem desde sua formação que é voltada aos interesses do capital, da exploração do trabalho e alinhada aos interesses do mercado.

A articulação entre educação e meio ambiente no Brasil ainda é cercada por desafios a serem superados e embora as limitações pedagógicas existentes sejam fruto do modelo de alienação da prática capitalista de ensino, Loureiro (2004) afirma que por meio de uma educação ambiental crítica é que poderemos transformar a realidade.

Transformar a realidade está relacionado ao encurtamento das distâncias entre escola e comunidade, sendo a problemática socioambiental um dos caminhos que permitem ao sujeito enxergar a crise existente ao seu redor, compreendendo sua parcela de contribuição no meio em que faz parte, das alternativas disponíveis para a quebra de paradigmas e principalmente para a articulação de processos colaborativos de resolução de problemas locais (DA COSTA; LOUREIRO, 2007; LOUREIRO, 2003; 2004; 2019).

Em resumo, as discussões da associação da vulnerabilidade com a justiça ambiental permitem que os riscos e situações perigosas moralmente inaceitáveis por serem evitáveis permitem com que estratégias de enfrentamento possam ser articuladas por meio da educação ambiental (PORTO; FREITAS; BARCELLOS, 2004).

Ao citar a Educação ambiental como ferramenta para o enfrentamento da crise socioambiental em que a pobreza, a desigualdade, a vulnerabilidade e a invisibilidade se fazem presentes, é preciso 
ter em mente que a educação ambiental não deve ser desvinculada da educação, tampouco deve ser vista como ferramenta atrelada única e exclusivamente as técnicas e instrumentos utilizados no processo pedagógico de ensino-aprendizagem, mas sim representando o processo educativo escolhido desde as escolhas ideológicas, pedagógicas e, metodológicas (LOPES; AMBIVERO, 2017).

\section{CONSIDERAÇ̃̃ES FINAIS}

Neste trabalho foram compartilhadas as reflexões provenientes do levantamento teórico que permitiu a construção da dissertação desenvolvida no Programa de Mestrado em Práticas em Desenvolvimento Sustentável da UFRRJ, buscando ampliar a compreensão sobre os temas que se desdobram acerca da desigualdade e da pobreza como a exclusão, vulnerabilidade e injustiças socioambientais.

Ao contextualizar diferentes autores e áreas, apontando que a dinâmica destrutiva do capital aprofunda e intensifica os processos de exploração tanto dos sujeitos quanto do meio ambiente, objetivou-se apontar que as contradições do capital precisam ser enxergadas e analisadas. Assumiu-se, assim que as desigualdades sociais e ambientais constituem-se em uma das faces provenientes da acumulação primitiva.

Assim, durante a exposição foram apresentados conceitos que permanecem relevantes e que são necessários para o fortalecimento do diálogo referente ao enfrentamento ao modelo capitalista de desenvolvimento exposto ao longo do artigo como insustentável.

Por essa razão, ao se pensar em desenvolvimento sustentável é necessário primeiramente refletir quanto à importância da formulação e a implementação de políticas sócio-econômica-ambientais, posto que há áreas distintas e subpopulações envolvidas nessas decisões "rumo ao desenvolvimento" que se restringem a aliviar a pobreza ao invés de superá-las.

Nesse processo, cabe destacar que práticas voltadas para a promoção de um "desenvolvimento sustentável” só serão efetivas a partir do momento em que as questões referentes à insustentabilidade socioambiental são discutidas, tendo em vista a adaptação do capitalismo e seu modo de produção.

Dessa forma, ao trazer a educação ambiental como ferramenta de sensibilização dos sujeitos, assume-se que por meio de uma visão crítica do sistema há a oportunidade de enfrentamento das forças hegemônicas, com uma reflexão sobre o sistema capitalista exploratório no qual a sociedade está imersa e a proposição de soluções para a quebra do ciclo de produção e consumo que tem aprofundado a segregação social.

\section{REFERÊNCIAS}

ABDALLA, M. M.; FARIA, A. Engajando com o lado mais sombrio do mercado e da gestão. Encontro da Anpad, 38, 2014. Anais[...], 2014.

ACSELRAD, H. Justiça ambiental: narrativas de resistência ao risco social. In: Encontros e

Caminhos: formação de educadoras(es) ambientais e coletivos educadores. Brasília: MMA, 2005. 
ALMEIDA, V. H.; GURGEL, F. F. In: CAVALCANTE, S.; ELALI, G. A. (org.). Psicologia ambiental: Conceitos para a leitura da relação pessoa-ambiente. Petrópolis: Vozes, 2018. 269 p.

ALVES, J. B. A face oculta do lixo. Londrina: Mecenas, 2017.

AMBIVERO, M. C. História oral dos moradores afetados pelo AHE Simplício - Queda única, Três Rios: contribuições para a educação ambiental. 2016. Dissertação (Mestrado em Psicossociologia de Comunidade e Ecologia Social) - Universidade Federal do Rio de Janeiro, Rio de Janeiro, 2016.

BARONI, M. Ambigüidades e deficiências do conceito de desenvolvimento sustentável. Revista de Administração de Empresas, São Paulo, v. 32, n. 2, p. 14-24, 1992.

BARROS, R. P.; MACHADO, A. F.; MENDONÇA, R. S. P. de. A desigualdade da pobreza: estratégias ocupacionais e diferenciais por gênero. 1997.

BRUNDTLAND, Gro Harlem; COMUM, nosso futuro. Relatório Brundtland. Our Common Future: United Nations, 1987.

CARVALHO, I. C. Movimentos sociais e políticas de meio ambiente. A educação ambiental aonde fica? Fórum De Educação Ambiental, 3, 1995, São Paulo. Cadernos[...], São Paulo: Gaia, 1995.

COHN, Amélia. As políticas sociais no governo FHC. Tempo Social, v. 11, n. 2, p. 183-197, 1999.

DA COSTA, César Augusto Soares; LOUREIRO, Carlos Frederico Bernardo. Educação ambiental crítica e interdisciplinaridade: a contribuição da dialética materialista na determinação conceitual. Revista Terceiro Incluído, v. 3, n. 1, p. 1-22, 2013.

DAGNINO, R. S.; JOHANSEN, I. C. Os catadores no Brasil: características demográficas e socioeconômicas dos coletores de material reciclável, classificadores de resíduos e varredores a partir do censo demográfico de 2010. 2017.

ESCOREL, Sarah. Vidas ao léu: trajetórias de exclusão social. SciELO-Editora FIOCRUZ, 1999.

GIDDENS, A. Modernidade e identidade. Tradução Plínio Dentzien. Rio de Janeiro: Zahar, 2002. 236 p.

HERCULANO, S. Riscos e desigualdade social: a temática da Justiça Ambiental e sua construção no Brasil. Encontro da ANPASS, 2002. Anais[...], Indaiatuba: SP, 2002.

JACOBI, P. R.; TRISTÃO, M.; FRANCO, M. I. G. C. A função social da educação ambiental nas práticas colaborativas: participação e engajamento. Cad. Cedes, Campinas, v. 29, n. 77, p. 63-79, 2009. 
LAYRARGUES, P. P. Educação ambiental com compromisso social: o desafio da superação das desigualdades. Repensar a educação ambiental: um olhar crítico. São Paulo: Cortez, 2009. p. 11-31.

LITTLE, P. Os conflitos socioambientais: um campo de estudo e de ação política. In: BURSZTYN, M. (org.). Difícil sustentabilidade. Política energética e conflitos ambientais. Rio de Janeiro: Garamond, 2001.

LOPES, V. F. M. Território, identidade socioterritorial, conflito e (in)justiça socioambiental. In: ADDOR, F.; HENRIQUES, F. C. (Org.) Tecnologia, participação e território: reflexões a partir da prática extensionista. Rio de Janeiro: UFRJ, 2015.

LOPES, A. F.; AMBIVERO, M. C. A educação ambiental e o papel gestor ambiental. Diversidade e Gestão, v. 1, n. 1, p. 51-56, 2017. Volume Especial Gestão Ambiental: Perspectivas, Conceitos e Casos.

LOUREIRO, Carlos Frederico B. Educação ambiental: questões de vida. São Paulo, Cortez. 2019.

LOUREIRO, Carlos Frederico B. Educação ambiental crítica: contribuições e desafios. Conceitos e práticas em educação ambiental na escola, p. 65, 2007.

LOUREIRO, Carlos Frederico B. Educação ambiental e gestão participativa na explicitação e resolução de conflitos. Gestão em Ação, Salvador, v. 7, n. 1, p. 37-50, jan./abr. 2004.

LOUREIRO, Carlos Frederico Bernardo. Premissas teóricas para uma educação ambiental transformadora. 2003. Disponível em: http://repositorio.furg.br/handle/1/6736 Acesso em: 10 mar. 2021.

MARX, K. Para a crítica da economia política. São Paulo, 1999. Coleção Os Pensadores

NASCIMENTO, E. P. Dos excluídos necessários aos excluídos desnecessários. In: BURSZTYN, M. (org.). No meio da rua: nômades excluídos e viradores. Rio de Janeiro: Garamond, 2000. p. 56-87.

NINO, Mozart Florêncio de Siqueira. Capital e trabalho: a dimensão humana do desenvolvimento socioeconômico sustentável. São Paulo: Paco Editorial, 2019.

PAUGAM, S. et al. Por uma sociologia da exclusão social: o debate com Serge Paugam. São Paulo: EDUC, 1999. $142 \mathrm{p}$.

PORTO, M. F. S.; FREITAS, C. M.; BARCELLOS, C. ACSELRAD, H. (org.). Conflito social e meio ambiente no Estado do Rio de Janeiro. Rio de Janeiro: Relume; Dumará: Fundação Heinrich Böll, 2004. 
SANTANA, Naja Brandão. Crescimento econômico, desenvolvimento sustentável e inovação tecnológica: uma análise de eficiência por envoltória de dados para os países do BRICS. 2012. Tese (Doutorado) - Universidade de São Paulo, São Paulo, 2012.

SANTOS, E. L. et al. Desenvolvimento: um conceito em construção. DRd-Desenvolvimento Regional em debate, v. 2, n. 1, p. 44-61, 2012.

SCALON, C. Desigualdade, pobreza e políticas públicas: notas para um debate. Revista Semestral do Departamento e do Programa de Pós-Graduação em Sociologia da UFSCar, v. 1, n. 1, p. 49, 2011.

SCHRODER, Jean Carlos et al. Os objetivos de desenvolvimento sustentável enquanto legado e aperfeiçoamento dos objetivos de desenvolvimento do milênio da organização das Nações Unidas. Relações Internacionais-Florianópolis, 2015.

SOARES, Laura Tavares. Os custos sociais do ajuste neoliberal na América Latina. 3. ed. São Paulo: Cortez, 2009.

VILAÇA, Natalia Machado; LOPES, Alexandre Ferreira. A implantação do Porto do Açu: um estudo de caso sobre os conflitos ambientais do $5^{\circ}$ Distrito de São João da Barra/RJ a partir das falas dos atingidos. Boletim do Observatório Ambiental Alberto Ribeiro Lamego, 2018. DOI: 10.19180/2177-4560.v12n22018p335-360. 
1 Mestra pela Universidade Federal Rural do Rio de Janeiro - UFRRJ no Programa de Pós-Graduação em Práticas em Desenvolvimento Sustentável (2020); Doutoranda pela Pontifícia Universidade Católica do Rio de Janeiro - PUC - RIO no Programa de Pós-Graduação em Serviço Social (2021); Bacharel em Administração Pública pela Universidade Federal Fluminense - UFF. E-mail: bomorais@gmail.com

2 Doutor em Ecologia (2009) pela Universidade Federal do Rio de Janeiro - UFRJ; Mestre em Ecologia (2004); Licenciado em Ciências Biológicas (2002); Atuou como professor de Ciências Biológicas na Educação Básica, como professor substituto do Departamento de Ecologia da Universidade Federal do Rio de Janeiro entre 2005 e 2006 e como professor assistente do Departamento de Biologia da Universidade Federal do Ceará entre 2009 e 2010; Atua nas áreas de: Educação Ambiental, Educação no Processo de Gestão Ambiental Pública e Etnociências; Tem experiência, também, na área de Ensino de Ecologia, atuando principalmente nos seguintes temas: mediação didática, extensão universitária, e material didático; Atualmente é professor no Instituto Três Rios da Universidade Federal Rural do Rio de Janeiro, ministra as disciplinas Ecologia Geral, Educação Ambiental e Ecologia de Campo no curso de Gestão Ambiental e é professor vinculado ao Programa de Pós-graduação em Práticas em Desenvolvimento Sustentável - PPGPDS/UFRRJ.

E-mail: alexandrelopes@outlook.com

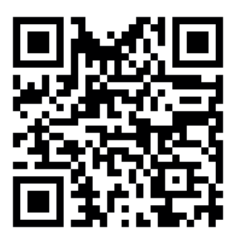

A autenticidade desse artigo pode ser conferida no site https://periodicos. set.edu.br

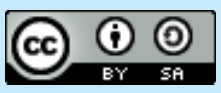

Este artigo é licenciado na modalidade acesso abertosob a Atribuição-Compartilhalgual CC BY-SA

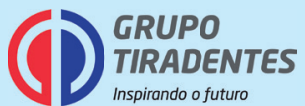

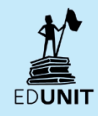

